\title{
Year in review 2014. Paediatric and adult clinical studies
}

\author{
Andy Bush, ${ }^{1}$ Ian Pavord ${ }^{2}$
}

${ }^{1}$ Imperial College London, MRC \& Royal Brompton Hospital, London, UK ${ }^{2}$ Respiratory Medicine Unit, Nuffield Department of Medicine, University of Oxford, Oxford, UK

\section{Correspondence to} Professor lan Pavord, Respiratory Medicine Unit, Nuffield Department of Medicine, University of Oxford, Oxford OX3 7FZ, UK; ian.pavord@ndm.ox.ac.uk

Accepted 2 February 2015

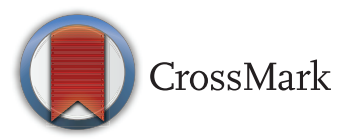

To cite: Bush A, Pavord I. Thorax 2015;70:368-372.
Our prizes for best papers in the last year have become as eagerly awaited as the Oscars and are much more glamorous. As before, we have awarded GOLD, SILVER and BRONZE prizes in the following categories: paediatrics, adult clinical, basic science and epidemiology. This is the first of two reviews of manuscripts published in Thorax in 2014 dealing with manuscripts on the clinical aspects of paediatrics and adult respiratory medicine. Decisions are purely those of the editors and deputy editors. Our only restriction has been to not consider manuscripts exclusively from Imperial and Oxford because we have conflicts of interest. Next month we deal with basic science and epidemiology manuscripts and reveal the overall winner.

\section{PAEDIATRIC YEAR IN REVIEW}

The year 2014 has featured a large number of strong paediatric manuscripts covering the whole range of respiratory medicine, including really important data on the early origins of adult lung disease. Patients with traditional 'paediatric' diseases, such as cystic fibrosis (CF) and Duchenne muscular dystrophy are now surviving into adult life, further blurring the barriers between adult and paediatric chest physicians. But nonetheless, this year has re-emphasised that aspects of what appears to be the same disease are different and show developmental changes. We cannot unlock the secrets of disease in children by studying adults.

The early bird gets an unwanted worm: Early life events are of huge importance long term. The Melbourne cohort has run for $>40$ years; and this year they showed that severe asthma at the age of 10 years is a bigger risk factor for COPD than smoking, at least in their cohort, and furthermore, at age 10 years the COPD adults had the lowest spirometry. ${ }^{1}$ Interestingly, the rate of decline of lung function did not seem different between the groups. Our editorialists highlight the key importance of optimising lung health early-a message that simply must reach the public domain. ${ }^{2}$ The Thorax take? If ever there was a demonstration of the futility of the umbrella diagnosis of COPD it is this paper-is non-atopic, smoking-related COPD really the same entity as premature airflow obstruction on a presumed background of previous eosinophilic inflammation?

Good news and bad news: Lung function may track from as early as 1 month of age until age 18 years, but also, as we are appreciating in other contexts, there is scope for some catch-up, especially in some of those who were the victims of maternal smoking in pregnancy. ${ }^{3}$ As with many observations, the importance is clear, but reversing the abnormalities is more challenging. ${ }^{4}$ We cannot change parental atopy; but we surely can do more about that old favourite, smoking. How many schoolchildren are taught that smoking may permanently harm your unborn baby (and even your baby's babies, if other studies are to be believed).

We all know that living in a rural community is a GOOD THING, don't we? Well, no-not if you live in Ecuador, where a great study challenged this paradigm. ${ }^{5}$ It looked like atopy and wheeze, but not rhinitis and eczema, were more common in rural children. The contrast with data from PARSIFAL and elsewhere is stark. These geographical variants must be telling us something, but what? This paper gets our Paediatric SILVER MEDAL, honouring research in testing conditions which challenges comfortable, developed world certainties.

CF-times they are a-changing: CF used to be diagnosed late in often severely symptomatic children, and management strategies were directed at firefighting the downstream consequences of the gene mutation. Now newborn diagnosis of well babies and direct targeting of the primary defect have come to the fore. But what happens after screening-doom and gloom according to the Australian AREST-CF team, with rapidly deteriorating lung function and evolving structural damage. Not so, say LCFC_-lung function actually improves over the first year of life, ${ }^{6}$ and HRCT changes are for the most part too mild to score. ${ }^{7}$ These two papers are our joint BRONZE MEDAL winners, not just for Science but for hitting back at the Australians after a five zip Ashes whitewash. Despite possessing the Wisdom of Solomon, our editorialist Peter Merkus was unable to resolve this Anglo-Australian controversy. ${ }^{8}$ The importance is that if AREST-CF is right, novel therapies should be trialled soon; if LCFC, the babies are doing so well that treatment can be deferred. Watch this space.

Ivacaftor directly targets class III mutations, and this year the indication for ivacaftor was extended from G551D to other, rarer gating mutations (another triumph for the clinical trial active CF community-an example to all disease groups). One criterion for acceptance on to the treatment programme is a reduction in sweat chloride (typically by around $50 \%$ in the published trials). However, Barry et $a l^{9}$ cast doubt on the wisdom of this by showing that there is no correlation between sweat chloride response and improvement in $\mathrm{FEV}_{1}$. So is CF lung disease really a disease of chloride transport? And if we assume wrongly that it is, will we pass up other promising treatments?

However, among the excitement of new horizons, attention to old problems is still essential. Diagnostic sophistication is ever greater, and 
confusion can multiply in consequence. The diagnosis of CF may be even harder despite multiple tests, and genetics may actually be the least informative approach, even using the 122 known disease causing mutations (out of around 2000 possible candidate changes in DNA at the CFTR locus). ${ }^{10}$ Prevention of cross-infection is essential in CF, but coughing spread actually spread Pseudomonas over a $4 \mathrm{~m}$ radius, with persistence for $45 \mathrm{~min}$, a considerable challenge to the $1-2 \mathrm{~m}$ assumed by current practice. ${ }^{11}$ The actual practical risk to patients as a result of not changing practice is unclear, but the challenge remains to optimise clinic conditions to reduce risk while maintaining efficiency and actually seeing more than one patient in an afternoon. ${ }^{12}$ Time and The International Depression Epidemiological Study (TIDES) wait for no man-is depression and anxiety commoner in $\mathrm{CF}^{13}$ or is this paper fundamentally flawed? ${ }^{14}$ Read both for yourself and watch the correspondence columns with bated breath! CF lung attacks-see Thorax passim (a previous issue for the classical ignoramus) may well lead to a permanent decrement in lung function, are associated with accelerated decline in spirometry and a worse prognosis-and may be predicted by an elevation in lung clearance index (LCI).$^{15}$ Prediction is one thing, stopping them is another, not addressed-but perhaps we should be using LCI clinically in this way? One barrier to prevention is the fact that many CF lung attacks are related to viral infections, even in adults. ${ }^{16}$ How badly we need effective and safe antiviral strategies for all-age patients!

The Grim Reaper: (or sickle cell disease (SCD), a big global player in non-infective morbidity and mortality in children). The prevalence of airway disease, usually labelled asthma, is said to be increased. However Chaudry et al ${ }^{17}$ showed that, although airflow obstruction is common and early in SCD, there is no evidence of airway hyper-responsiveness or inflammation. Whatever this SCD airway disease, it is not conventional asthma-so please, please can we stop using the term? And, is SCD a primary airway not vascular disease? However, vascular abnormalities are clearly significant. Lunt $e t a l^{18}$ used HRCT to get a handle on pulmonary vascular volume and suggested that these may relate to some of the lung function abnormalities in SCD including changes over time. Acute chest syndrome in SCD comes in many radiographic forms. Mekontso Dessap et $a l^{19}$ found that consolidation was more severe in the apex and was more prevalent than ground glass change or atelectasis. Its presence was associated with a worse prognosis.

From the Department of Dirty Tricks: Who but the tobacco industry takes pole position here? Nick Hopkinson has a great track record for getting in the face of the industry (no Knighthood for you, Nick!), and he and colleagues looked at the uptake of smoking by children across the country-67 A DAY in London alone. ${ }^{20}$ What is Government doing (other than procrastinating) in the face of this industry triumph? Taking the tobacco shilling (or a rather larger currency note)? Queen's Awards for Industry and Trebles all round.

Of course there is more to pollution than tobacco, and more to Governmental kid gloves than schmoozing the tobacco industry. Near roadway air pollution adversely affects children's lung function, independent of regional pollution. ${ }^{21}$ What a surprise! Who would have thought it? Although our editorialists properly urge caution with regard to some of the methodology, ${ }^{22}$ a question: what is there to be lost by keeping traffic well away from residential areas? And a much more difficult question-why don't politicians break off their thundering tirades about the iniquities of the National Health Service, which seem to persist despite (because of?) the mandarins 'reforming' it for quarter of a century with a degree of purpose which make headless chickens look like Einstein, and actually pass legislation that would help children? Answers in a letter to Thorax, please, and beware of low flying pigs!

Severe 'asthma' in children: Why are a few children with asthma so difficult to treat, even when prescribed treatment is actually taken and the pet cat disenfranchised? Pollution leads to the accumulation of carbon particles in alveolar macrophages, but there is less carbon in macrophages of children with severe asthma. ${ }^{23}$ Is this due to impaired macrophage function in these children? The authors speculate that the mechanism may be via elevation in $\mathrm{PGE}_{2}$ in severe asthma. Is the problem a failure of resolution of inflammation? Gupta $e t a l^{24}$ showed that BAL interleukin (IL)-10 levels in severe asthma were positively correlated with serum vitamin D levels, and vitamin D enhanced steroid-induced IL-10 production by peripheral blood mononuclear cells. IL-17A was not affected-is it friend or foe in severe asthma? And will vitamin D deliver the goods therapeutically?

Turning the air (or at least the patient) blue: Old fashioned physiology-the anatomical shunt test (the patient breathes $100 \%$ oxygen and peripheral arterial saturation is measured at equilibrium) is a good first-line screening test when compared with more sophisticated or invasive tests. ${ }^{25}$ What about saturation studies in hereditary haemorrhagic telangiectasia (HHT)? This condition may be more common that once thought, with an estimated UK prevalence of at least one in $9500 .^{26}$ We all learn about orthodeoxia as a diagnostic test, but actually, although possibly useful in examinations and for ward round show-offs, it is not useful in children with HHT. ${ }^{27}$ Not so in adults; orthodeoxia was common, as was orthostatic tachycardia, which was associated with better exercise tolerance, for reasons that are obscure to this writer. ${ }^{28}$ Extrapolate across the age spectrum at your (or your patient's) peril.

Going Viral! The dangers of extrapolation, part 2. It has long been suggested that asthmatics have reduced respiratory epithelial cell production of $\beta$-interferon (IFN) and $\lambda$-IFN in response to viral infections. Not so in young atopic children; they do have a defect in viral clearance, but it is not related to IFN and is virus specific. ${ }^{29}$ Importantly, responses vary at different levels of the respiratory tract, highlighting the importance of paediatricians actually doing paediatric research, and not being content with low-hanging fruit (in this case, nasal epithelial cells). ${ }^{30}$

Treatment of viral infections is a big problem. A real light SABRE-nebulised hypertonic saline is recommended as a great treatment for RSV bronchiolitis-and so it is, according to the SABRE study, with one slight problem-it doesn't work! ${ }^{31}$ Perhaps this study was helped by avoiding the problems of previous work, which used a placebo which made babies worsealways a good way to show benefit for an ineffective intervention. The SABRE group can dance for joy-they win the Paediatric GOLD MEDAL for 2014 for a practice changing, definitive paper in an important field. In this context, Cunningham and Unger ${ }^{32}$ pointed out the virtues of doing original research, rather than endlessly meta-analysing the work of others, a sentiment with which your editors would certainly agree. If we can't treat bronchiolitis, can we prevent it? Maybe we can if we optimise the management of pregnant women with asthma by measuring exhaled nitric oxide, ${ }^{33}$ although this finding requires confirmation.

The Best of the Rest: There were a number of important papers which do not fit into the above categories. MDR TB is a real threat—and so it was encouraging to read that $>90 \%$ of 
infected children can be treated successfully using an individualised approach. ${ }^{34}$ With the threat of drug-resistant TB, should we not optimise prevention with BCG? ${ }^{35}$ Worryingly, one in three high-risk infants did not receive BCG. Time for a change? Anything to be lost from a blanket policy of immunising all babies?

Get it right for children and you'll get it right for adults? Alternatively, never work with children. Pneumococcal community-acquired pneumonia in adults was associated with contact with children, but pneumococcal vaccination of the children had the spin-off of protecting adults. ${ }^{36}$ So the kids get the pain (of injection), the adults the gain-same for paediatricians and adult physicians, perhaps?

Lastly, silent night or snoring night? Obstructive sleep apnoea (OSA) in children was once so simple, they had fat tonsils, fat bodies or both. Tan $e t a^{37}$ discussed the much greater complexities of phenotyping paediatric OSA in the modern era, in a mind-stretching review.

And finally: never work with children or animals! So the finale is the report showing that racehorses with Heaves, a better biological model than mice although rather more demanding to work with, have an altered smooth muscle heavy chain isoform which is reversed by inhaled steroids. ${ }^{38} \mathrm{~A}$ special Thorax prize for the most ingenious medication delivery device, provided it is actually demonstrated while riding a Heaving Horse!

\section{ADULT CLINICAL YEAR IN REVIEW}

Marking time? 2014 has been a good year for biomarker research, with a number of contenders for our prestigious 2014 BIOMARKER OF THE YEAR AWARD. Encouragingly an increasing number of manuscripts describe biomarkers that are associated with clinically important outcomes and identify treatment opportunities. The sputum-serum hydrogen sulfide ratio looks like a robust and measureable biomarker of neutrophilic airway inflammation in patients with $\mathrm{COPD},{ }^{39}$ potentially a clinically important pattern of airway inflammation. More compellingly, a blood thrombocytosis was found to be associated with increased mortality in patients hospitalised with a COPD lung attack. ${ }^{40}$ This effect was seemingly independent of cardiovascular mortality and was not present in patients taking antiplatelet agents, elevating the findings into the potentially clinically very important category. For this reason, and because the biomarker count is routinely measured, the blood platelet count wins our biomarker of the year award. Serum and pleural fluid fibulin 3 and mesothelin had less good years, winning the 'nice try, pity about the data' award. Creaney et $a l^{41}$ showed that these molecules performed significantly less well as diagnostic and prognostic markers in malignant mesothelioma than earlier studies had suggested, emphasising the importance of validation studies. Hellyer et $a l^{42}$ performed an excellent biomarker discovery and validation study in patients with ventilator-associated pneumonia, finding that low serum IL-1b and IL-8 effectively excluded this condition. Finally, ${ }^{3} \mathrm{He}$ MRI demonstrated that ventilator defects were seen in the patients with more severe asthma studied by Svenningsen et al. ${ }^{43}$ Whether these defects identify airways that could be usefully treated with bronchial thermoplasty is a key remaining question.

We also had several strong papers describing new outcome measures or further validating existing instruments. The ultimate outcome measure is to visualise the pathological process directly in vivo. Cosio et al, ${ }^{44}$ in our SILVER MEDAL paper in this category, show that this might be possible in patients with COPD using a standard broncoscopy and fibred confocal florescence microscopy. Patient reported outcome measures are also much to the fore. The clinical COPD questionnaire looks like a simple, quick to measure quality of life questionnaire with a bigger effect size following pulmonary rehabilitation that other, more cumbersome but better known instruments. ${ }^{45}$ Many of our patients with COPD find themselves attending for a CT chest and the number will increase with lung cancer screening. The presence of coronary artery calcification was found to be associated with increased COPD-associated symptoms and mortality and evidence of increased systemic inflammation. ${ }^{46}$

Will your editors score? Other new outcome measures including a new symptom scale for patients with COPD suitable for daily use $;{ }^{47}$ a scoring system capable of predicting survival in patients with malignant pleural effusions; ${ }^{48}$ a lung-transplant specific quality of life score ${ }^{49}$ and an ultrasonic technique for assessing diaphragmatic thickness and likelihood of successful weaning in patients requiring mechanical ventilation. ${ }^{50}$ The radiographic pattern of connective tissue disease-associated interstitial lung disease was shown to be heterogeneous by Saketkoo et $a l^{51}$ Understanding this heterogeneity is a priority before progress can be made with treatment, as is the identification of potential outcome measures. Saketkoo $e t a l^{51}$ provide an excellent evaluation of the likely candidates.

Trials and tribulations? Once armed with the right outcome measures and biomarker of the pathogenic process, the clinician is in a strong position to carry out the killer clinical trial. We had a particularly strong crop of these in $2014 . .^{52-60}$ The pick of these, and the winners of our BRONZE and GOLD MEDALS in this category, are two large, definitive trials with surprising findings (always the best sort of clinical trial). The BRONZE MEDAL winner ${ }^{61}$ found that inhaled mannitol, previously shown to be beneficial in patients with CF, had no effect on exacerbations of non-CF bronchiectasis. This finding together with earlier similar findings with inhaled DNAse emphasises that $\mathrm{CF}$ and bronchiectasis are very different. The GOLD MEDAL winner by Struik et $a l^{62}$ investigated the effect of nocturnal noninvasive ventilation following a hospital admission with a COPD lung attack and persistent hypercapnoea. Treatment reduced nocturnal and day time $\mathrm{pCO}_{2}$ but had no effect on readmission rates or death. Congratulations to the authors for carrying out a demanding and clinically very important study.

Your editors are perhaps not alone in finding the process of meta-analysis (ie, picking over the bones of other peoples hard work until a striking but highly unlikely finding emerges) hugely overrated as a means for identifying clinically important effects. We published three such analyses in 2014, both a cut well above the usual. Yu et $a l^{63}$ performed an analysis of FDA data on the effects of roflumilast in COPD, finding a $0 \%$ probability of benefit across different categories of patients but a 50\% probability of a $>22 \%$ reduction in COPD lung attacks in patients with a prior history of $>1$ attack in the last year; lung attacks as important are an ongoing theme. Bratton et al $l^{64}$ carried out a meta-analysis of individual data from trials of CPAP treatment in minimally symptomatic OSA. They found no evidence that CPAP reduced blood pressure in the whole population, although it did result in symptomatic benefit. There was a small but significant effect on blood pressure in the subgroup who used CPAP for $>4 \mathrm{~h}$. Finally, Gimeno-Santos et $\mathrm{al}^{65}$ were largely unsuccessful in identifying determinants of physical activity in patients with COPD despite performing an exhaustive analysis of 86 studies.

In contrast, observational studies, particularly those from highly expert and busy centres, are a greatly underrated form of 
medical evidence. A good example is the study by Bridevaux et $a l^{66}$ investigating viral infections in lung transplant recipients. These occurred frequently, commonly involved Picornavirus and were associated with temporary reduction in lung function, but not with rejection. We also highlight a careful analysis of outcomes after pulmonary endarterectomy showing an association between the amount of material removed surgically and shortterm, but not long-term, improvement in pulmonary vascular resistance; $;^{58}$ and a large study showing that the presence of residual DVT, right heart strain, hypotension, and hypoxia are risk factors for early (but again not late) deterioration following a pulmonary embolus. ${ }^{67}$ Observational studies can be especially interesting if the data are analysed in an innovative way. A cluster analysis of the COPD gene cohort identified potentially more informative phenotypes from a genetic point of view; ${ }^{68}$ and a study using clinician-derived multidimensional indices confirmed that the new 2011 GOLD ABCD classification of COPD is less good than the BODE index as a predictor of mortality. ${ }^{69}$ Two studies tackled the effect of obesity on the lung. An excellent physiological study showed dramatically increased oesophageal and gastric pressures, reduced FRV and ERV and markedly increased work of breathing. ${ }^{70}$ An important clinical manifestation of this is obesity hypoventilation, which Hollier et $a l^{71}$ showed worsened in a dose-dependent manner when treated with supplementary oxygen. Finally, observational studies come into their own when from centres dealing with rare or unfamiliar conditions. Pien $e a^{72}$ showed that sleep disordered breathing in pregnancy should perhaps be in neither of these categories, as it complicates $10.5 \%$ of pregnancies in the first trimester and $26.7 \%$ in the third. Increased maternal age and Body Mass Index were predictable risk factors. Atypical carcinoid tumours sit more comfortably in the rare and unfamiliar category. Canizares $\mathrm{et}_{\mathrm{al}} \mathrm{l}^{73}$ provided some welcome guidance on management by showing that they were less likely to recur when treated with lobectomy and radical lymphadenectomy.

\section{Competing interests None.}

Provenance and peer review Commissioned; internally peer reviewed.

\section{REFERENCES}

1 Tai $A$, Tran $H$, Roberts $M$, et al. The association between childhood asthma and adult chronic obstructive pulmonary disease. Thorax 2014;69:805-10.

2 Mattes J, Gibson PG. The early origins of COPD in severe asthma: the one thing that leads to another or the two things that come together? Thorax 2014:69:789-90.

3 Turner $S$, Fielding $S$, Mullane $D$, et al. A longitudinal study of lung function from 1 month to 18 years of age. Thorax 2014;69:1015-20.

4 Henderson AJ. The child is father of the man: the importance of early life influences on lung development. Thorax 2014;69:976-7.

5 Cooper PJ, Vaca M, Rodriguez A, et al. Hygiene, atopy and wheeze-eczema-rhinitis symptoms in schoolchildren from urban and rural Ecuador. Thorax 2014;69:232-9.

6 Nguyen TT, Thia LP, Hoo AF, et al. Evolution of lung function during the first year of life in newborn screened cystic fibrosis infants. Thorax 2014;69:910-17.

7 Thia LP, Calder A, Stocks J, et al. Is chest CT useful in newborn screened infants with cystic fibrosis at 1 year of age? Thorax 2014;69:320-7.

8 Merkus PJ. Setting the stage for CFTR modulator studies in infants. Thorax 2014;69:888-90.

9 Barry PJ, Jones AM, Webb AK, et al. Sweat chloride is not a useful marker of clinical response to Ivacaftor. Thorax 2014;69:586-7.

10 Ooi $C Y$, Dupuis $A$, Ellis L, et al. Does extensive genotyping and nasal potential difference testing clarify the diagnosis of cystic fibrosis among patients with single-organ manifestations of cystic fibrosis? Thorax 2014;69:254-60.

11 Knibbs LD, Johnson GR, Kidd TJ, et al. Viability of Pseudomonas aeruginosa in cough aerosols generated by persons with cystic fibrosis. Thorax 2014;69:740-5.

12 Jones AM. Airborne dissemination of transmissible bacterial species in cystic fibrosis. Thorax 2014;69:690-1.

13 Quittner AL, Goldbeck L, Abbott J, et al. Prevalence of depression and anxiety in patients with cystic fibrosis and parent caregivers: results of The International Depression Epidemiological Study across nine countries. Thorax 2014;69:1090-7.
14 Webb AK, Bryon M. The International Depression Epidemiological Study (TIDES): unfinished business? Thorax 2014;69:1067-8.

15 Vermeulen F, Proesmans M, Boon M, et al. Lung clearance index predicts pulmonary exacerbations in young patients with cystic fibrosis. Thorax 2014;69:39-45

16 Flight WG, Bright-Thomas RJ, Tilston $P$, et al. Incidence and clinical impact of respiratory viruses in adults with cystic fibrosis. Thorax 2014;69:247-53.

17 Chaudry RA, Rosenthal M, Bush A, et al. Reduced forced expiratory flow but not increased exhaled nitric oxide or airway responsiveness to methacholine characterises paediatric sickle cell airway disease. Thorax 2014; 69:580-5.

18 Lunt A, Desai SR, Wells AU, et al. Pulmonary function, CT and echocardiographic abnormalities in sickle cell disease. Thorax 2014;69:746-51.

19 Mekontso Dessap A, Deux JF, Habibi A, et al. Lung imaging during acute chest syndrome in sickle cell disease: computed tomography patterns and diagnostic accuracy of bedside chest radiograph. Thorax 2014;69:144-51.

20 Hopkinson NS, Lester-George A, Ormiston-Smith N, et al. Child uptake of smoking by area across the UK. Thorax 2014;69:873-5.

21 Urman R, McConnell R, Islam T, et al. Associations of children's lung function with ambient air pollution: joint effects of regional and near-roadway pollutants. Thorax 2014:69:540-7.

22 Kunzli N. Effects of near-road and regional air pollution: the challenge of separation. Thorax 2014;69:503-4.

23 Brugha RE, Mushtaq N, Round T, et al. Carbon in airway macrophages from children with asthma. Thorax 2014;69:654-9.

24 Gupta A, Dimeloe S, Richards DF, et al. Defective IL-10 expression and in vitro steroid-induced IL-17A in paediatric severe therapy-resistant asthma. Thorax 2014;69:508-15.

25 Ming DK, Patel MS, Hopkinson NS, et al. The 'anatomic shunt test' in clinical practice; contemporary description of test and in-service evaluation. Thorax 2014;69:773-5

26 Donaldson JW, McKeever TM, Hall IP, et al. The UK prevalence of hereditary haemorrhagic telangiectasia and its association with sex, socioeconomic status and region of residence: a population-based study. Thorax 2014;69:161-7.

27 Carpenter S, Josepovici J, Latino G, et al. Positional oximetry to screen for pulmonary arteriovenous malformations in HHT. Thorax 2014;69:1045.

28 Santhirapala V, Chamali B, McKernan H, et al. Orthodeoxia and postural orthostatic tachycardia in patients with pulmonary arteriovenous malformations: a prospective 8-year series. Thorax 2014;69:1046-7.

29 Spann KM, Baturcam E, Schagen J, et al. Viral and host factors determine innate immune responses in airway epithelial cells from children with wheeze and atopy. Thorax 2014:69:918-25.

30 Saglani S. Innate immunity in paediatric viral wheezers is virus specific and not interferon dependent. Thorax 2014;69:887-8.

31 Everard ML, Hind D, Ugonna K, et al. SABRE: a multicentre randomised control trial of nebulised hypertonic saline in infants hospitalised with acute bronchiolitis. Thorax 2014;69:1105-12.

32 Cunningham S, Unger SA. Nebulised hypertonic saline in bronchiolitis: take it with a pinch of salt. Thorax 2014;69:1065-6.

33 Mattes J, Murphy VE, Powell $H$, et al. Prenatal origins of bronchiolitis: protective effect of optimised asthma management during pregnancy. Thorax 2014;69:383-4.

34 Sharma S, Chhabra D, Kho AT, et al. The genomic origins of asthma. Thorax 2014;69:481-7.

35 Nguipdop-Djomo P, Mangtani P, Pedrazzoli D, et al. Uptake of neonatal BCG vaccination in England: performance of the current policy recommendations. Thorax 2014;69:87-9.

36 Rodrigo C, Bewick T, Sheppard C, et al. Pneumococcal serotypes in adult non-invasive and invasive pneumonia in relation to child contact and child vaccination status. Thorax 2014;69:168-73.

37 Tan H-L, Kheirandish-Gozal L, Gozal D. The promise of translational and personalised approaches for paediatric obstructive sleep apnoea: an 'Omics' perspective. Thorax 2014;69:474-80.

38 Boivin R, Vargas A, Lefebvre-Lavoie J, et al. Inhaled corticosteroids modulate the (+)insert smooth muscle myosin heavy chain in the equine asthmatic airways. Thorax 2014;69:1113-19.

39 Saito J, Mackay AJ, Rossios C, et al. Sputum-to-serum hydrogen sulfide ratio in COPD. Thorax 2014;69:903-9.

40 Harrison MT, Short P, Williamson PA, et al. Thrombocytosis is associated with increased short and long term mortality after exacerbation of chronic obstructive pulmonary disease: a role for antiplatelet therapy? Thorax 2014;69:609-15

41 Creaney J, Dick IM, Meniawy TM, et al. Comparison of fibulin-3 and mesothelin as markers in malignant mesothelioma. Thorax 2014;69:895-902.

42 Hellyer TP, Conway Morris A, McAuley DF, et al. Diagnostic accuracy of pulmonary host inflammatory mediators in the exclusion of ventilator-acquired pneumonia. Thorax 2015;70:41-7

43 Svenningsen $\mathrm{S}$, Kirby M, Starr D, et al. What are ventilation defects in asthma? Thorax 2014;69:63-71. 
44 Cosio BG, Shafiek H, Fiorentino F, et al. Structure-function relationship in COPD revisited: an in vivo microscopy view. Thorax 2014;69:724-30.

45 Kon SS, Dilaver D, Mittal M, et al. The Clinical COPD Questionnaire: response to pulmonary rehabilitation and minimal clinically important difference. Thorax 2014;69:793-8.

46 Williams MC, Murchison JT, Edwards LD, et al. Coronary artery calcification is increased in patients with COPD and associated with increased morbidity and mortality. Thorax 2014;69:718-23.

47 Galea A, Durran A, Adlan T, et al. Practical applications of digital tomosynthesis of the chest. Clin Radiol 2014;69:424-30.

48 Gesthalter YB, Vick J, Steiling K, et al. Translating the transcriptome into tools for the early detection and prevention of lung cancer. Thorax. Published Online First: 27 Jan 2015. doi:10.1136/thoraxjnl-2014-206605.

49 Singer JP, Blanc PD, Dean YM, et al. Development and validation of a lung transplant-specific disability questionnaire. Thorax 2014;69:437-42.

50 DiNino E, Gartman EJ, Sethi JM, et al. Diaphragm ultrasound as a predictor of successful extubation from mechanical ventilation. Thorax 2014;69:423-7.

51 Saketkoo LA, Mittoo S, Huscher D, et al. Connective tissue disease related interstitial lung diseases and idiopathic pulmonary fibrosis: provisional core sets of domains and instruments for use in clinical trials. Thorax 2014;69:428-36.

52 Lazarinis N, Jorgensen L, Ekstrom T, et al. Combination of budesonide/formoterol on demand improves asthma control by reducing exercise-induced bronchoconstriction. Thorax 2014;69:130-6.

53 Bateman ED, O'Byrne PM, Busse WW, et al. Once-daily fluticasone furoate (FF)/ vilanterol reduces risk of severe exacerbations in asthma versus $\mathrm{FF}$ alone. Thorax 2014;69:312-19.

54 Osadnik CR, McDonald CF, Miller BR, et al. The effect of positive expiratory pressure (PEP) therapy on symptoms, quality of life and incidence of re-exacerbation in patients with acute exacerbations of chronic obstructive pulmonary disease: a multicentre, randomised controlled trial. Thorax 2014;69:137-43.

55 Sillen MJ, Franssen FM, Delbressine JM, et al. Efficacy of lower-limb muscle training modalities in severely dyspnoeic individuals with COPD and quadriceps muscle weakness: results from the DICES trial. Thorax 2014;69:525-31.

56 Deslee $\mathrm{G}$, Klooster $\mathrm{K}$, Hetzel $\mathrm{M}$, et al. Lung volume reduction coil treatment for patients with severe emphysema: a European multicentre trial. Thorax 2014;69:980-6.

57 Kang HJ, Hwangbo B, Lee GK, et al. EBUS-centred versus EUS-centred mediastinal staging in lung cancer: a randomised controlled trial. Thorax 2014;69:261-8.

58 Skoro-Sajer N, Marta G, Gerges C, et al. Surgical specimens, haemodynamics and long-term outcomes after pulmonary endarterectomy. Thorax 2014;69:116-22.
59 Chapman JL, Kempler L, Chang CL, et al. Modafinil improves daytime sleepiness in patients with mild to moderate obstructive sleep apnoea not using standard treatments: a randomised placebo-controlled crossover trial. Thorax 2014;69:274-9.

60 Quinnell TG, Bennett M, Jordan J, et al. A crossover randomised controlled trial of oral mandibular advancement devices for obstructive sleep apnoea-hypopnoea (TOMADO). Thorax 2014;69:938-45.

61 Bilton D, Tino G, Barker AF, et al. Inhaled mannitol for non-cystic fibrosis bronchiectasis: a randomised, controlled trial. Thorax 2014;69:1073-9.

62 Struik FM, Sprooten RT, Kerstjens HA, et al. Nocturnal non-invasive ventilation in COPD patients with prolonged hypercapnia after ventilatory support for acute respiratory failure: a randomised, controlled, parallel-group study. Thorax 2014;69:826-34.

$63 \mathrm{Yu}$ T, Fain K, Boyd CM, et al. Benefits and harms of roflumilast in moderate to severe COPD. Thorax 2014;69:616-22.

64 Bratton DJ, Stradling JR, Barbé F, et al. Effect of CPAP on blood pressure in patients with minimally symptomatic obstructive sleep apnoea: a meta-analysis using individual patient data from four randomised controlled trials. Thorax 2014

65 Gimeno-Santos E, Frei A, Steurer-Stey C, et al. Determinants and outcomes of physical activity in patients with COPD: a systematic review. Thorax 2014;69:731-9.

66 Bridevaux PO, Aubert JD, Soccal PM, et al. Incidence and outcomes of respiratory viral infections in lung transplant recipients: a prospective study. Thorax 2014;69:32-8.

67 Kabrhel C, Okechukwu I, Hariharan P. Factors associated with clinical deterioration shortly after PE. Thorax 2014;69:835-42.

68 Castaldi PJ, Dy J, Ross J, et al. Cluster analysis in the COPDGene study identifies subtypes of smokers with distinct patterns of airway disease and emphysema. Thorax 2014;69:415-22.

69 de Torres JP, Casanova C, Marin JM, et al. Prognostic evaluation of COPD patients: GOLD 2011 versus BODE and the COPD comorbidity index COTE. Thorax 2014;69:799-804.

70 Steier J, Lunt $\mathrm{A}$, Hart N, et al. Observational study of the effect of obesity on lung volumes. Thorax 2014;69:752-9.

71 Hollier CA, Harmer AR, Maxwell LJ, et al. Moderate concentrations of supplemental oxygen worsen hypercapnia in obesity hypoventilation syndrome: a randomised crossover study. Thorax 2014;69:346-53.

72 Pien GW, Pack Al, Jackson N, et al. Risk factors for sleep-disordered breathing in pregnancy. Thorax 2014;69:371-7.

73 Canizares MA, Matilla JM, Cueto $A$, et al. Atypical carcinoid tumours of the lung: prognostic factors and patterns of recurrence. Thorax 2014;69:648-53. 